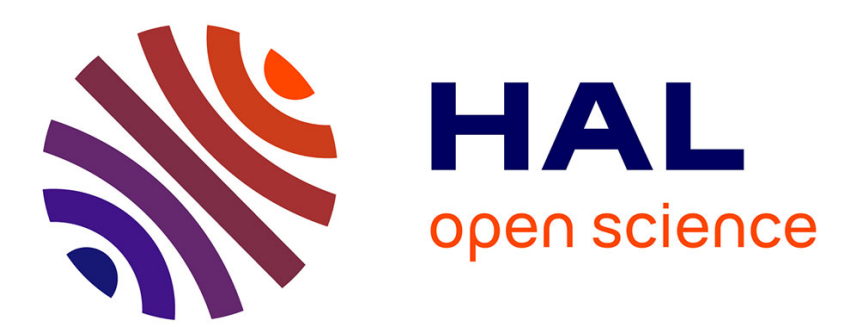

\title{
Towards a Semantic Documentation of Heritage Objects through Visual and Iconographical Representations
}

\author{
Nicola Carboni, Livio de Luca
}

\section{To cite this version:}

Nicola Carboni, Livio de Luca. Towards a Semantic Documentation of Heritage Objects through Visual and Iconographical Representations. International Information and Library Review, 2017, 49, pp.207 - 217. 10.1080/10572317.2017.1353374 . hal-02863361

\section{HAL Id: hal-02863361 https://hal.science/hal-02863361}

Submitted on 2 Jul 2020

HAL is a multi-disciplinary open access archive for the deposit and dissemination of scientific research documents, whether they are published or not. The documents may come from teaching and research institutions in France or abroad, or from public or private research centers.
L'archive ouverte pluridisciplinaire HAL, est destinée au dépôt et à la diffusion de documents scientifiques de niveau recherche, publiés ou non, émanant des établissements d'enseignement et de recherche français ou étrangers, des laboratoires publics ou privés. 


\title{
Towards a Semantic Documentation of Heritage Objects through Visual and Iconographical Representations
}

\author{
Nicola Carboni and Livio de Luca \\ Modèles et simulations pour l'Architecture et le Patrimoine, CNRS, Marseille, France
}

\begin{abstract}
The recording of cultural heritage objects' data and information is constructed throughout the registration of different media items, which function as an anchor of the original object in digital space. The article investigates the application of a theoretical framework for the organization of information related to the visual works, on the base of the identity of their single constituent elements. The framework is, then, used for the formalization of an ontology which is constructed as an extension of CIDOC-CRM. The result is tested with information gathered over the Asinou Church in Cyprus, expressed throughout an ontology for recording propositions over the iconographical attributes and the characteristic of images.
\end{abstract}

\author{
Keywords \\ Art history; CIDOC-CRM; \\ cultural heritage; \\ iconography; ontology; \\ semantics
}

\section{Introduction}

The recording of the information related to a digital heritage object is constructed throughout the registration of different m edia i tems ( photo, video, text, or $3 \mathrm{D}$ reconstruction), which function as an anchor and representative in a digital space of the original object/phenomena. The cataloguing, organization, and archiving of such information is of paramount importance, not only for their future retrieval but also for exposing, revealing, and integrating this set of information, as well as provide the domain specialists with tools for clustering and organizing them. Nowadays, however, the recording practice endorse the use of metadata based structure (Baca, Harpring, Lanzi, McRae, \& Whiteside, 2006; Lubas, Jackson, \& Schneider, 2013) that result in a series of flattened object-centric descriptors which, even if they in a way relate to the same phenomenon, fail to fully describe an object in relation to its context, providing to the final users only a partial account of its complexity.

Overcoming the weakness of such structures will require, in the first place, dropping the objectcentric approach and making a shift towards an event/ process-centric representation (Kettula \& Hyvönen, 2012), while enforcing the use of semantic systems able to record the relationships between the described enti-ties. Such shift would ensure a clearer and distinctive description of the documentation process, and not just of the result of the process itself: the document.

While text-based objects have received a great deal of attention during the last years, the work of normalization and integration of information regarding visual items, even if $2 \mathrm{D} / 3 \mathrm{D}$ representations are the main media used to digitally represent objects, is still 
quite limited. Several tools and frameworks for the classification/normalization of $\mathrm{i}$ mages w ere 1 ately developed and used, but unfortunately, those tools reflect the aforementioned object-centric vision, and, moreover, do not take into account the semiosis of the picture, therefore, lacking one the most important features for their comprehension. The incorporation of such attributes within the classification practice would create new means for their discoveries and their automatic collection.

Art history, and in particular iconography, would help at great length on such challenge. The accumulation of a substantial body of literature and knowledge in the last century in regard to the study of subjects and meanings of works of art is, in fact, of primary importance in the understanding of the relationships between a representation, considered as a whole, and the collections of details that convey its identity, both as a picture and as an historical and social document. Iconography is at the core of this multidisciplinary effort, and the contributions of the main actors in the field are essential for the development of a working system which would allow the research, clustering, and comparison of visual items.

\section{Literature review}

One of the earliest approaches to the analysis and interlinking of both knowledge representation and iconographical art was made by D'Andrea and Ferrandino (2007) the authors attempted to map and reuse concept from both the International Committee for Documentation-Conceptual Reference Model (CIDOC-CRM) and the Descriptions \& Situations (D\&S) extension of DOLCE developed by Gangemi and Mika (2003) in order to extract image meaning throughout knowledge representation methods using $\mathrm{D} \& S$ for adding information in regard to the context and state-of-affairs of a specific representations. While the work was quite promising, no further development was carried out, leaving the community with just a promising summary of a possible work.

Even if restricted to the Byzantine icons domain, the study of Tzouveli, Simou, Stamou, and Kollias (2009) is worth citing as one of the first and more complete works in the field. The authors, in fact, used fuzzy description logic to determine features in Byzantine icons and map those features to an OWL ontology. However, the features identified a re $\mathrm{j}$ ust $\mathrm{l}$ abels, and no structure or identity criteria is provided in order to understand and aggregate pictures. Moreover, the study, as the authors highlight, is limited to basic and formal structure such as the one depicted in Byzantine icons, limiting the applicability to more complex scenarios.

Interesting is also the solution developed by De Luca et al. (2013) during the analysis and documentation of the tomb of Emperor Qianlong in China. The initial investigation, in fact, revealed that the engravings and iconographies of the tomb were arranged in order to reflect the Buddhist Tibetan funerary ritual; their layout and spatial position reflects the deposit of religious text within a stupa. To visually show this kind of relationship a virtual stupa was created and put in relationships with the final 3D model in order to allow the interlinking between spatial elements and their conceptual counterpart. Additionally, a graph-like interface was created in order to browse the conceptual elements linked to the physical representation. While not using formal representation methods this solution demonstrates the possibility given by a semantic description of iconographical features. However, even in this case, no identity criteria for recognizing and aggregating pictures is provided.

Probably the most comprehensive solution is the one developed for the Fototeca Zeri in Bologna (Daquino, Mambelli, Peroni, Tomasi, \& Vitali, 2016; Gonano, Tomasi, Mambelli, Vitali, \& Peroni, 2014; Mambelli, 2014) for the PHAROS project (Reist, Farneth, Stein, \& Weda, 2015).

While exposing the Zeri Photo the authors developed two ontologies (F Entry ontology and OA ontology) to map data coming from two Italian standards developed by the Istituto Centrale per il Catalogo e la Documentazione (or Central Institute for the Cat-aloguing and Documentation in English), the Scheda di Fotografia (or Photography Entry in English), and Scheda Opera d'Arte (or Work of Art Entry in English). The two ontologies were mapped with CIDOCCRM, as well as Historical Context Ontology (HiCO) (Daquino \& Tomasi, 2015), Publishing Roles Ontology (PRO) (Peroni, Shotton, \& Vitali, 2012), and FRBRaligned Bibliographic Ontology (FaBIO) (Per-oni \& Shotton, 2012), which guarantee the possibility to add information related to respectively the prove-nance of assertions, the roles of the agents dealing with the artworks and the position of the object in rela-tion to the Functional Requirements for Bibliographic 
Records (FRBR) model. Moreover, thanks to an extension and mapping between HiCO and PROV Ontology (PROVO) the ontology allows the recording of information in regard to the influence between works of art. This work is excellent and seems to touch diverse needs in the art-historian community, but it does not take into account the description of the features and attributes that greatly would help in the retrieval and aggregation of visual items.

\section{Methodology}

Art history and iconography are essential for the creation of a framework of description, but the tools in use in the art historical tradition, such as ICONCLASS (van de Waal, 1973), the Warburg Classification System (Duits, 2014), and the Thesaurus Iconographique of Garnier (Garnier, 1984), use the same object-centric and flat structure aforementioned. Moreover, those tools are normally biased towards a specific art historian tradition. While this is not a problem per se, it comes to be an issue when we start to use them in an integrative framework for querying and clustering media files based on their symbolic composition. The main issue here is the dispersions of information, caused by the lack of harmonization of the sources. The different descriptions point to similar attributes which are, however, described differently. It is, therefore, necessary to create a top information structure for their integration, using a language that would allow a machine to categorize items as common members of a specific group/category. In order to achieve such goal, it is important to establish a functional logical theory that would formalize the meaning of a vocabulary and its relation to a particular conceptualization of the world.

While for centuries providing a neutral means of presenting conceptualizations and allowing reasoning and description in a certain domain was the typical work of logic and mathematics, during the second half of the 20th century, and mostly from the 1970s (Hoekstra, 2009) computer science, and in particular the sub-field of artificial intelligence, begins to adopt and re-develop this tools in order to try to construct systems able to exploit the definition of formal propositions with the aim of building rich knowledge base. The field has come to be known as knowledge representation, which has been defined as "the application of logic and ontology to the task of constructing computable models for some domain" (Sowa, 2000).
Knowledge representation is, therefore, a functional methodology for translating language statements into computable representations using tools from computer science, philosophy, and logic. Specifically, it relies on a functional (Zúñiga, 2001) conceptualization of the world (implied in any information system) which is specified in a well-founded formal ontology, meaning a:

logical theory accounting for the intended meaning of a formal vocabulary, i.e. its ontological commitment to a particular conceptualization of the world. The intended models of a logical language using such a vocabulary are constrained by its ontological commitment. An ontology indirectly reflects this commitment (and the underlying conceptualization) by approximating these intended models. (Guarino, 1998, p. 5)

The use of an ontology allows the classification of the statements asserted by various actors/social groups, providing the shared ground for a group of specialists to enrich and compare each other's documentation.

Such a shift from flat documentation to a n ontologically founded documentation structure provide the prerequisite to the unification of different discourses into a flexible system, able to fully represent the richness of the disciplines involved in the analysis of the object and, thus, met the challenge in their full meaning. Moreover, this method gives the possibility to transform the recorded assertions into a series of logical statements that can be interpreted by a reasoner, which can infer implicit knowledge from the original records and augment them, in order to represent and reveal a richer network of relationships between the described elements.

\section{Theoretical foundation}

The application of this methodology to complex cultural heritage objects started gaining momentum during the latest years, but the role of visual items (such as motifs and iconographical atoms), and specifically their role in providing identity criteria for visual heritage, was not so well examined.

Develop a solid formal structure able to provide the necessary identity criteria for our visual heritage, as well as fully register the richness in its meaning is imperative. A way to approach the problem is through a theoretical foundation which would guide the development of schemas and other formal structure. The aim is the definition of a framework able to record the diverse 
identities and the sign relations present in visual items and to link them with the interpretation of a specialist, as well as with their historical/current context and with the performative actions that use them and throughout practice provide them with meaning.

In order to achieve this aim, it is essential to review and harmonize the current information framework used for the description of visual items with the art historian and semiotics interpretative theories in regard to our visual heritage. Following this step, the focus should be finally switched to the diverse methodologies for data formalization and integration.

\section{Iconographical analysis}

The work on the sign and a perception theory in art started with one of the fathers of the discipline: Panofsky. He identified three layers (Panofsky, 1939) present in the works of art which can be studied in order to gain more knowledge about the social, historical practice that guided the interpretation of a work of art. The study profoundly changed not only the art historical landscape, but it comes to influence several other disciplines, moreover, escorting the history of art in the realm of semiotics.

Following Eco's suggestion (1979) that iconography and iconology can be considered a fully formed chapter of semiotics, as well as the thought of some other semioticians who have noticed the congeniality of the analysis of Peirce and Saussure with the study of Riegl, Panofsky, and Schapiro (Bal \& Bryson, 1991), we rely our on the art historical theory for the foundation of our methodology. Specifically, we employ the theory developed by van Straten (1986) which slightly modif i ed Panofsky's ideas. Van Straten, in fact, reuses the three layers identified by Panofsky, but he added another one in order to clarify some of the ambiguities left unresolved by latter (Figure 1).

Van Straten does not challenge the first preiconographical phase of analysis, which identifies pure forms such as a certain configuration of lines or certain representation of an object, such as human being, which could be called the world of artistic motifs.

However, the iconographical analysis, which was for Panofsky the assignment of themes and concepts to the composition of artistic motifs-which are recognized to be the carrier of a conventional meaning-is divided by van Straten into two diverse analysis: the iconographical description (second phase) and interpretation (third phase).

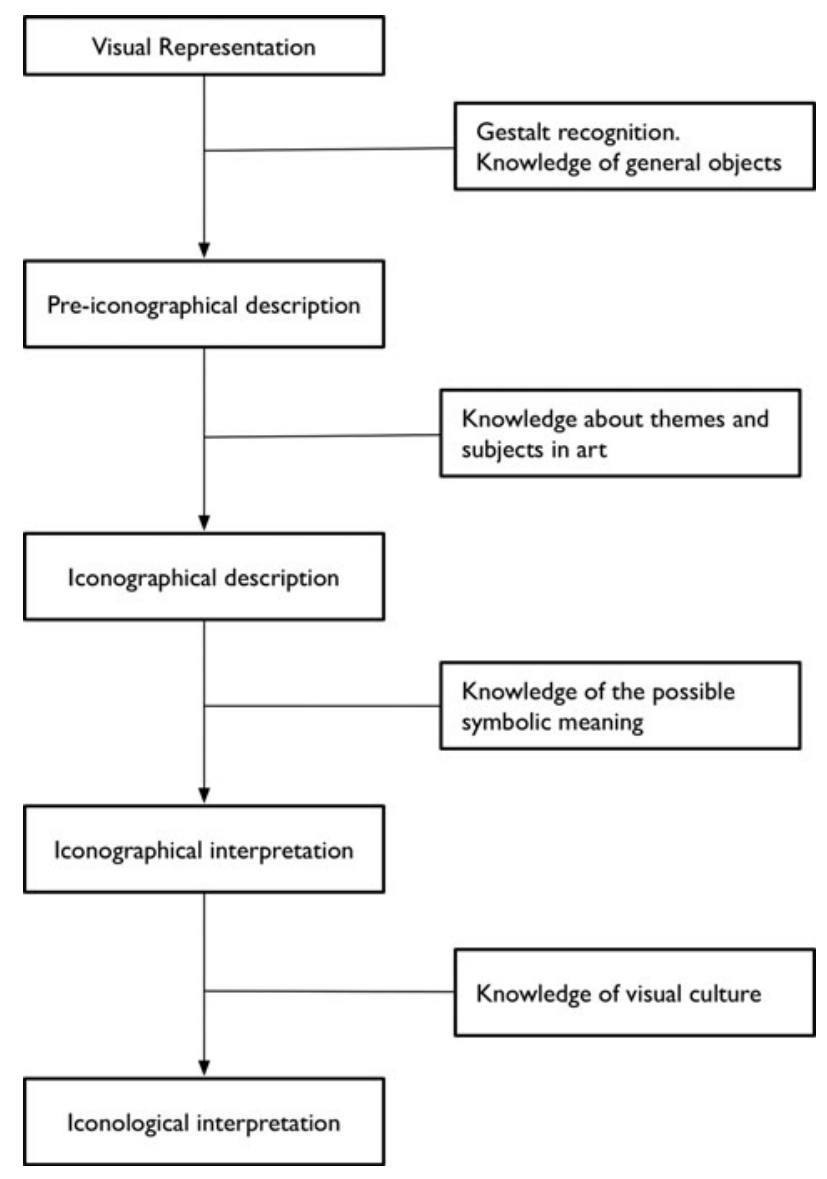

Figure 1. Calculating $h$-index (Alonso et al., .)9002

The iconographical description is the analytical phase where the subject of the representation is established (for example, "Diana and Actaeon"), but not deeper meaning is searched for. In this case, we can attribute an iconographical description to all the works of art, in contrast with the analysis of Panofsky, which recognize the possibility of assignment of a secondary subject matter only to a set of works of art (landscape, for example, did not allow any other analysis if not the first pre-iconographical one).

The iconographical interpretation examines the explicitly use of symbols by the artist and formalizes the deeper meaning of a representation. The fourth and final step of the analysis is the iconological interpretation and deal with those symbolic values which that are not explicitly intended by the artist, and are part of the visual culture of that time and can be analyzed historically and ethnographically.

Therefore, the signs are identified during the preiconographical phase throughout the identification of a specific artistic motif (which are itself symbols/icons) and act as formalized atom of a bigger structure. 
The second act of interpretation is the iconographical analysis, which requires a more specialized knowledge, and the use, in this case, of vocabularies of forms in order to describe the content of the image. These vocabularies do not have to be real external resources (such as we intend them nowadays), but they easily can be embedded in our experience and inherited in a social arena (see Bourdieu [1977] and Lemonnier [2012] for a more theoretical treaty on such subject).

The recognition of the meaning of the image is based on the identification of the diverse signs incorporated in the image, formalized by the artist through readymade code (Gombrich, 1994) usually consisting of sets of attributes and characteristics.

The combination of these attributes, such as objects, plants, animals, or other icons/symbols, help identify, in the work of art, a personification/characters in a specific situation/narrative.

Attributes can also help identify specif i c qualitie $s$ (kindness, rage, etc.) of the depicted character, or his belonging to a distinct group (blacksmith, noble, saint, etc.). The use and harmonization of this combination have helped the creation of iconographical types, pro-viding the tools for the identification/ classification of diverse representations (Polidoro, 2008; van Straten, 1994).

The theoretical framework, here briefly recorded, need to be translated into an information framework to be used for the creating classes and properties and, then, modeling an object. The first phase of analysis (see Table 1 for a mapping between object of interpretation, act, and information requirements) should provide only the physical understanding of the object/gestalt under analysis and it will have to be translated into a morphological and spatial assumption made on the physical object (we would call this the process of identification of an iconographical atom).

The iconographical analysis has to be seen instead as the assignment of a specif i c term to a certain type of $\mathrm{f} i$ gure. This process typically involves the association of the iconographical atom with a conceptual object that identifies it. The identification is terminological and it uses specific vocabularies (ICONCLASS, etc.) where the definitions of the diverse subjects a re formalized. The iconographical interpretation takes place with the identification of the various characters (allegories or personification) on the base of their attributes and characteristics. In order to make the link between the element clear and re-usable in our further analysis and queries, it is important to associate and classify the atoms that constitute a figure. Their link to a specific character would help define his identity in a specific time/space on the base of the recorded elements.

The name of the elements itself should be chosen by a prescribed source. The iconological interpretation would be instead done by the researcher using the data aggregated thanks to the type of schema which result from our work.

For being functional, the above theoretical stance needs to be translated into an ontological model that would ensure its applicability on a diverse range of object/situations. In order to make it compatible to the diversity of semantic resources already available, it was structured as an extension of CIDOC-CRM (2015; Doerr, 2003), a standard ontology in the cultural heritage domain.

CIDOC-CRM is an empirically defined ontology focused on the cultural heritage domain, functioning as a framework for data integration within several cultural organizations. It is organized in entity types and relationships, and it will allow us to display the degree of interconnection between the entities that take part in the production and interpretation of visual items. Furthermore, it gives us the possibility to expand it with extensions and to use different modules, which have been already developed, such as CRMGeo (Doerr \& Hiebel, 2013) for the description of spatial informa-tion and FRBRoo (Bekiari, Doerr, Le Bouf, \& Riva, 2015) for the documentation of the different entities that gravitate around the library worlds.

Table 1. From interpretation to information

\begin{tabular}{|c|c|c|}
\hline Object of interpretation & Act of interpretation & Information requirements \\
\hline $\begin{array}{l}\text { Primary or natural subject matter - (A) factual, } \\
\text { (B) expressional—constituting the world of artistic motifs. }\end{array}$ & $\begin{array}{l}\text { Pre-iconographical description (and } \\
\text { pseudo-formal analysis). }\end{array}$ & Geometrical qualities (Denotation) \\
\hline \multirow{2}{*}{$\begin{array}{l}\text { Secondary or conventional subject matter, constituting the } \\
\text { world of images, stories and allegories. }\end{array}$} & Iconographical analysis & Subject identification \\
\hline & Iconographical interpretation & $\begin{array}{l}\text { Iconographical and Symbolic value } \\
\text { (Attributes and Connotation) }\end{array}$ \\
\hline $\begin{array}{l}\text { Intrinsic meaning or content, constituting the world of } \\
\text { 'symbolical' values. }\end{array}$ & Iconological interpretation & Automatic Inductive Reasoning \\
\hline
\end{tabular}




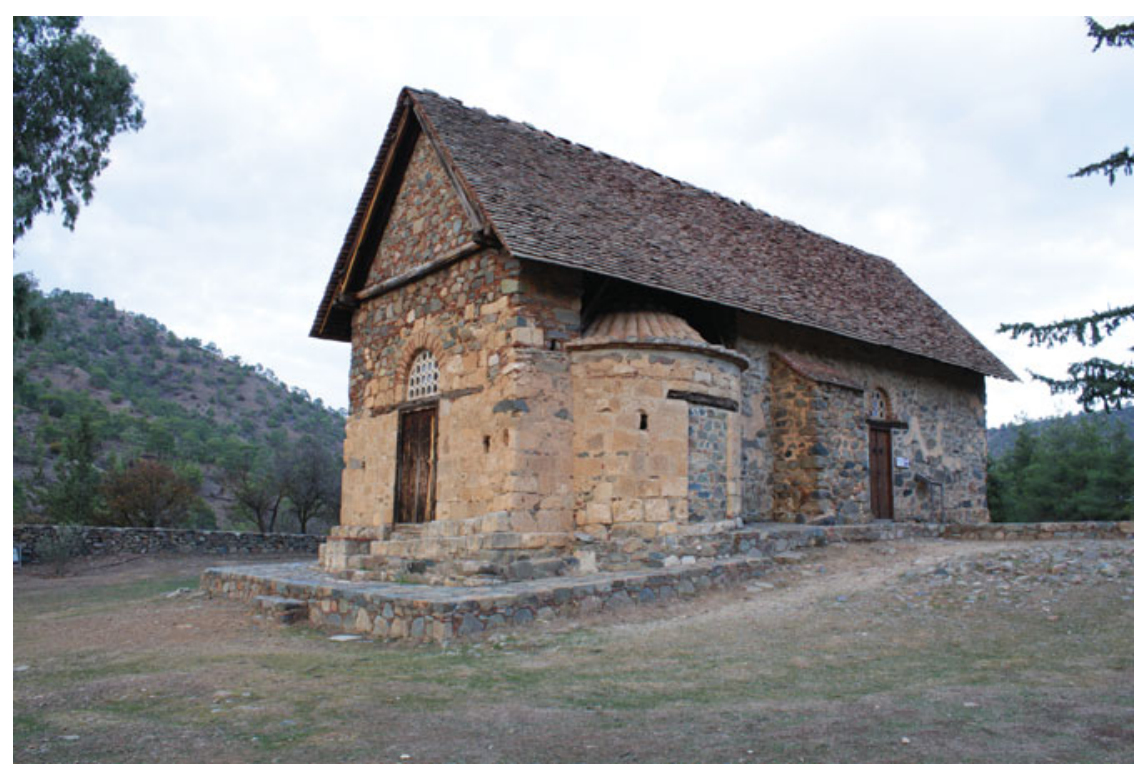

Figure 2. Exterior of the church of Asinou, Cyprus.

Regarding the reliability of the documentation structure, CIDOC-CRM is an International Organization for Standardization (ISO) standard and is the results of 20 years of development under the aegis of the International Council of Museums (ICOM). CIDOCCRM would, moreover, help us encode the various assertion in different semantic spaces, therefore, differentiating the propositions that refer to a physical object from the meaning assigned to them by an interpreter (for an extensive explanation, see Carboni \& De Luca [2016]).

\section{Case study: Panagia Phorbiotissa, Cyprus}

A real-world scenario, the church of Panagia Phorbiotissa in Cyprus, would be used for testing the validity of this ontological work. The testing would rely on the collection of data gathered during the analysis of the church. This church (Figure 2) appears to be, in fact, a perfect case-study for such work. Known also by the appellation of Asinou it is as rich in paintings in the interior as it is humble on the exterior. The interior walls (Figure 3 ) are covered by frescoes that range from

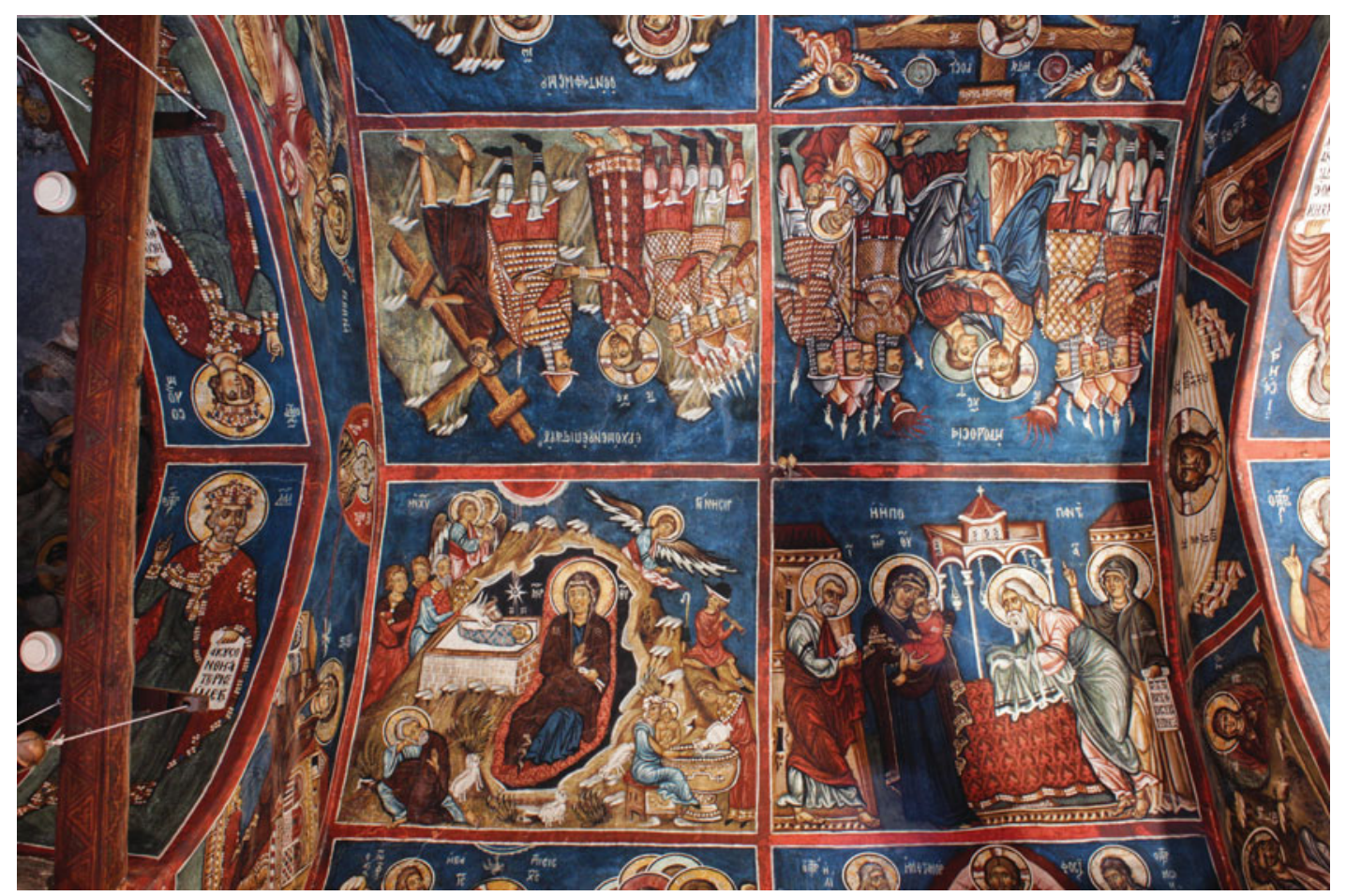

Figure 3. Interior wall paintings of the church of Asinou, Cyprus. 
12th (foundation) to early 17 th century, displaying a wide abundance in themes and details, which reflect the history of the country itself. This same richness allows an exploration not only of the artworks but also on the relation to the frescoes with other mural programs in Cyprus, highlighting the dialogue within the Byzantine imagery in the country, as well as abroad. For its importance and its beauty, it has been inscribed from 1985 in the UNESCO World Heritage Site List, together with 10 other churches in the same area (Troodos Mountain in Cyprus; Carr \& Nicolaïdès, 2012; Stylianou \& Stylianou, 1985).

In order to focus on the methodology and do not shallowly describe every possible visual element in the church, we will use as an example one single small wall painting, the panel of Anastasia, situated on the wall of the south apse of the narthex of the church (Figure 4).

The panel of Anastasia, chosen here for its iconographical representativeness, picture St. Anastasia Pharmakolyitria holding a white martyr cross and a white bottle. She is commonly called with the epithet "dissolver of potion," and the overall figure is iconographically linked to the concept of healing. Next to her is placed Anastasia Saramalina, one of the several donors of the church (Carr \& Nicolaïdès, 2012).

\section{Ontological analysis and development: Visual and iconographical representations}

In order to record the diverse statements in relation to the panel of Anastasia we introduced a new ontology: visual and iconographical representations (VIR).

VIR extend CIDOC-CRM (2015) with the formalization of the relationships between diverse visual representations and symbols that define our visual culture. VIR relies on the semiotic distinction between visual signs and their interpretation, as well as on an art-historical theoretical framework previously introduced for defining the inter-relationships between atomic elements that compose visual items, defining, therefore, a set of criteria for the identification and clusterization of figures in art.

By using a combination of CIDOC-CRM and VIR, it is possible to record statements (and associate them with $2 \mathrm{D} / 3 \mathrm{D}$ representations) about the physical and conceptual nature of the heritage, interrelating infor-mation about its morphological, visual, and contextual identity.

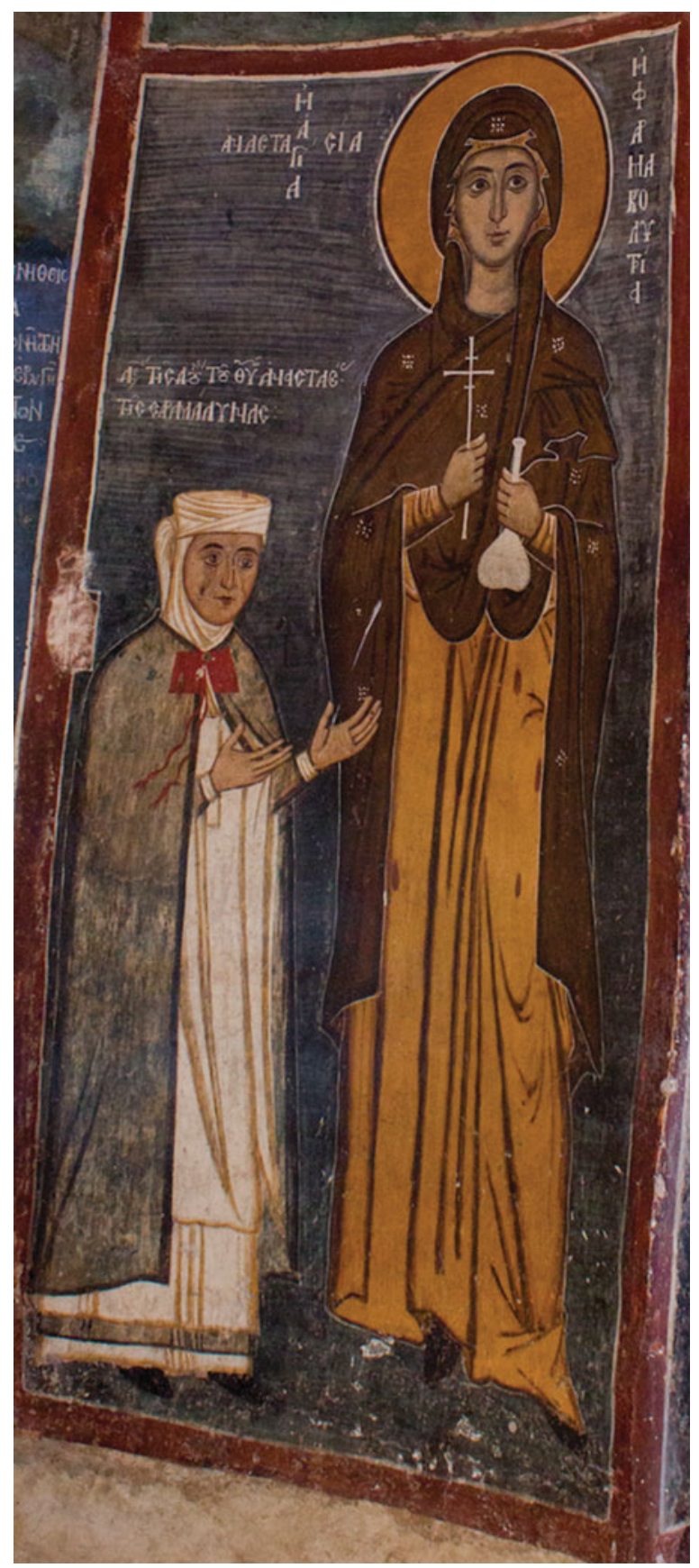

Figure 4. The panel of Anastasia and Anstasia, Asinou.

In order to provide an example of the possibilities given by this new ontology, a set of information about the panel of Anastasia in Asinou (using Carr \& Nicolaïdès [2012], as the main source) have been recorded and formalized using VIR's ontological structure. The preliminary results are presented in Figures 6, 7, and 8.

The purpose of these graphs is to provide to the reader an example of application of the developed information framework, as well as display how the information present in just a small portion of a wall 


\begin{tabular}{|l|l|l|}
\hline Prefixes & \\
\hline http://www.cidoc-crm.org/cidoc-crm/ & C & P \\
http://iflastandards.info/ns/fr/frbr/frbroo/ & C & P \\
http://www.ics.forth.gr/is//CRMgeo/ & C & P \\
http://itndch.map.archi.fr/VIR/ & C & P \\
\hline
\end{tabular}

Figure 5. Legend of the ontology used in subsequent graphs.

painting if correctly described, can help create that rich-information environment that opens the doors to new ways to document a heritage object in relation to its functional and visual context. For easy reading, we specify in Figure 5 the diverse ontology linked and used in the various graphs. The diversity is highlighted by the use of colors, which are specified in the legend. "C", in this case, stands for classes and "P" for properties.

The first graph (Figure 6) describes the process of creation of the wall painting, defining its temporal and spatial property together with the information in regards to the agency and the technique used. The result of the process is defined as "iconographical atom," which is a physical arrangement of forms/colors created by human activity. The iconographical atom (IC1) helps relate the physical dimension of the form with its interpretation. In this case, a specialist identifies the physical portion of the wall painting with a specific iconographical object (IC9), an identifiable set of nuclear characteristics of a particular visual element. The distinction between "atom" and "object" is of paramount importance for linking to the same physical form the diverse interpretations (encoded as diverse instances of IC9s) of a visual item.

A more detailed description of the IC9 (Figure 7), defining its relation to a portrayed "character" (IC16, in this case, Anastasia of Sirmium), as well as the nuclear elements that define the identity of the object: the iconographical attribute (IC10). The latter are essential characteristics for the identification of a visual element. Two IC9 (as shown in Figure 7) with the Monastery

of St. John Lampadistis, even if visually dif $\mathrm{f}$ erent, ca $\mathrm{n}$ be linked together by the use of the same attributes, unveiling the symbolic characteristic attributed to a specific character, and helping study the evolution of the conventions behind the depiction of certain visual item. The historical influence, together with the use of different elements in the depiction of certain charac-ters, can unveil the variations in the schemas and dic-tionaries used in diverse context, as well as the influences in the stylistic evolutions of objects.

The above operations are essential for the clusterization of images by high-level semantic properties, which are crucial for a wide scholarly study of the diversity of the history of visual culture and representation.

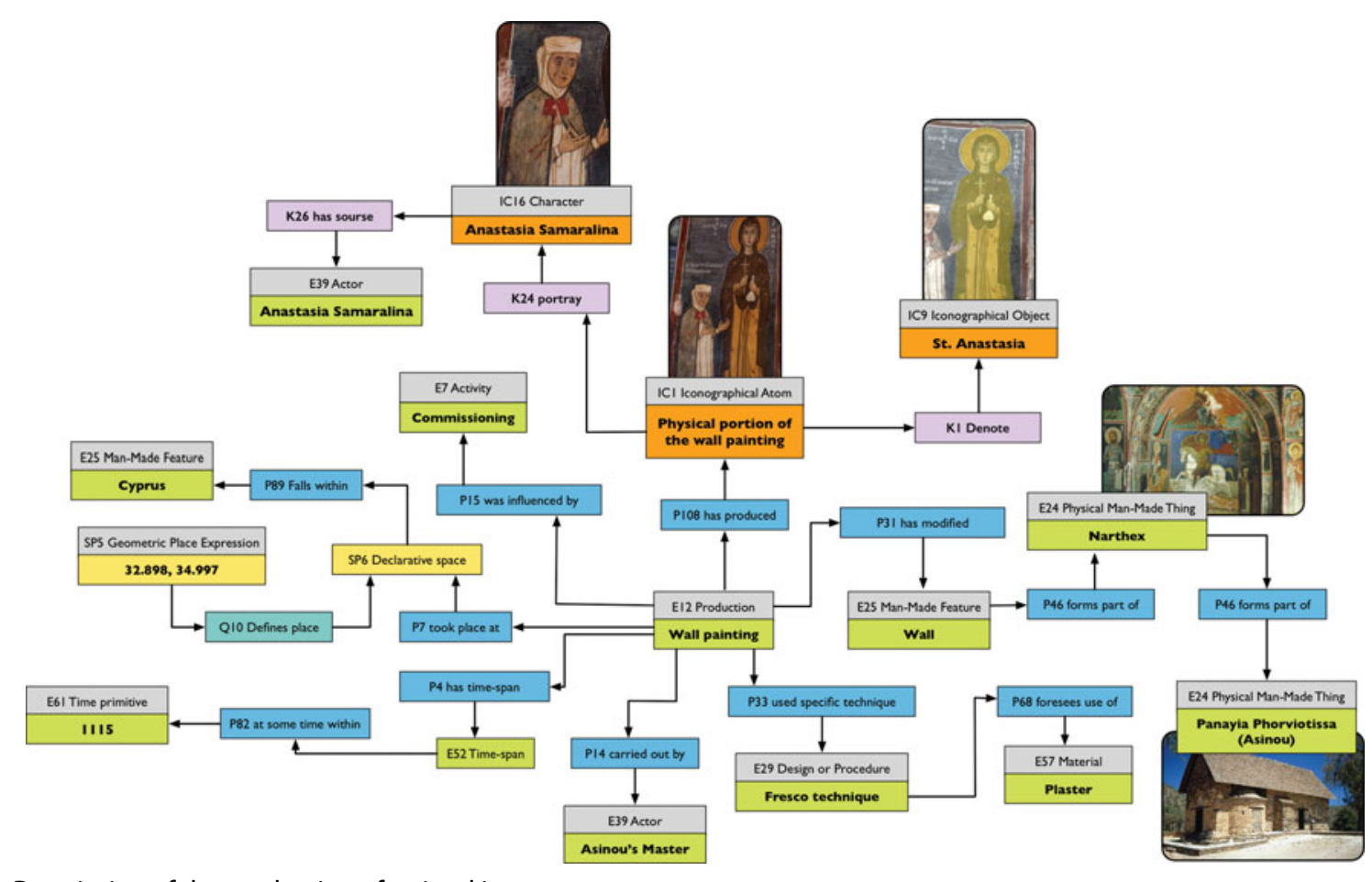

Figure 6. Description of the production of a visual item. 


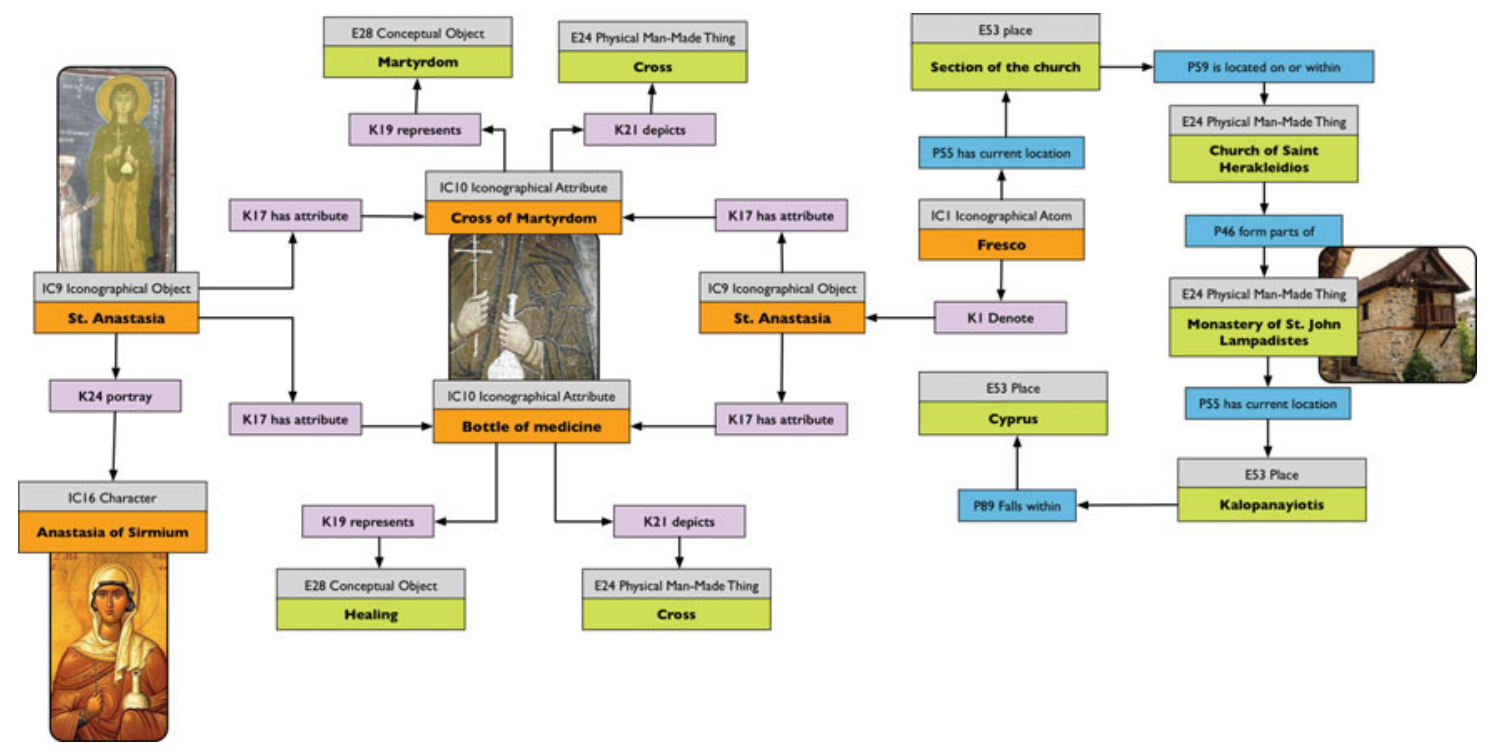

Figure 7. Attributes description and link with other representations.

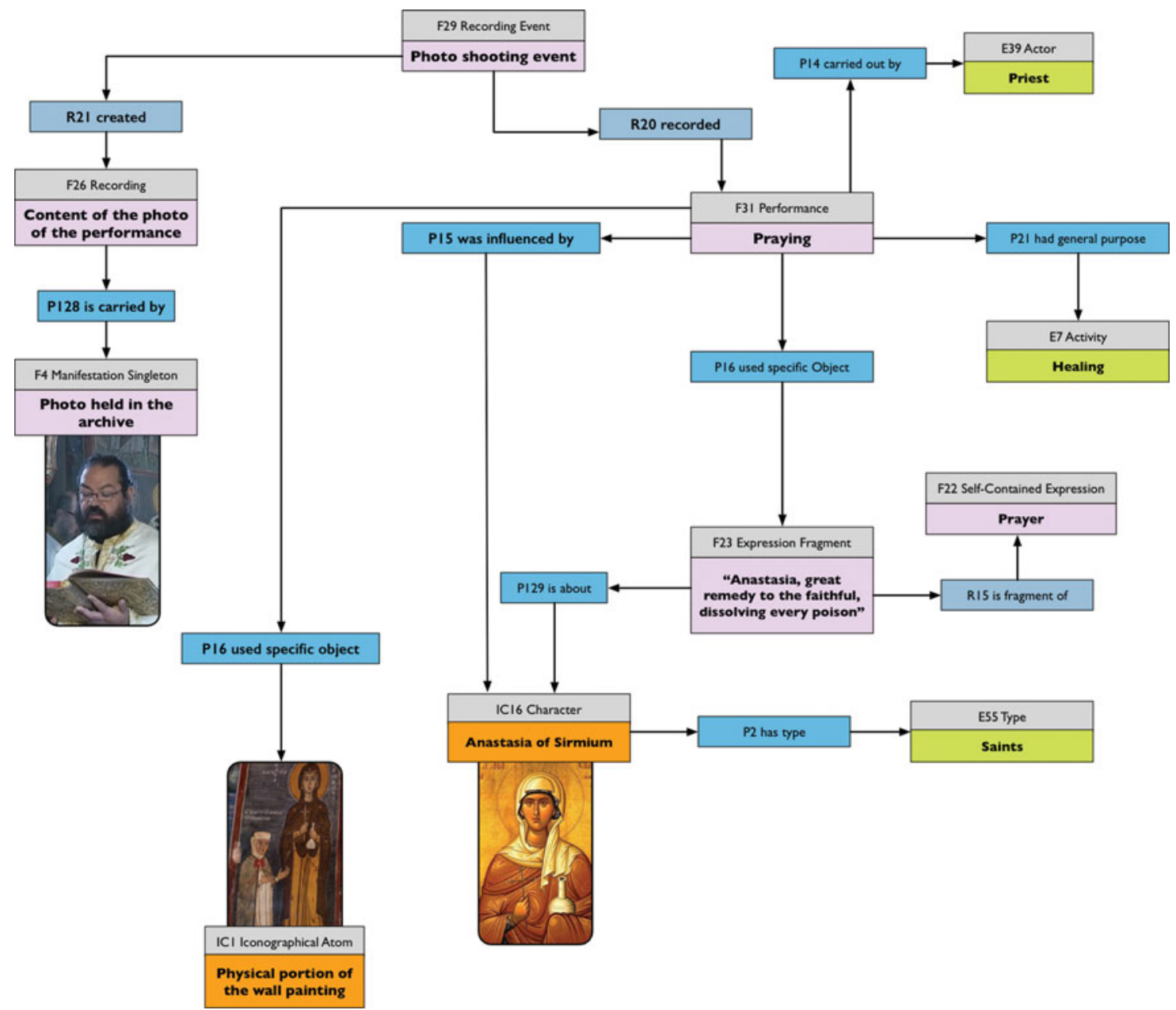

Figure 8. Relation of a visual item with a performance. 
The integration of information and the analysis of IC9 do not, however, resolve the issue of the description of a heritage object as a mere container (as in the architectural case) or gestalt (as with man-made objects). For overcoming such problem, it is necessary to relate the performative action that takes place within a certain heritage object with the physical forms/structures used for the construction of meaning. An example of this formalization can be found in Figure 8, where it is possible to see the relation between the panel of Anastasia (IC1) and the activity of praying (F31, performance) that took place in the church of Asinou.

Figure 8 shows that the performance use a specific prayer ("Anastasia, great remedy to the faithful, dissolving every poison"; Carr \& Nicolaïdès, 2012) to invoke the character of St. Anastasia. The invocation is directed throughout the IC9 (the panel) that depict the character of St. Anastasia, which is pictured with attribute (the cross) referring to healing properties. With such type of documentation, the performance is finally documented throughout the link with the wall painting, and with a specific architectural heritage, and not as a single unit, moreover, successfully associating the concept of healing with the praying towards a certain saint.

\section{Conclusion}

The above analysis showed the richness in information retrievable from a cultural object and, moreover, how it is possible to use knowledge representation techniques for combining that information in a semantic system.

The proposed approach allows the description of visual items using diverse granularities, their interconnection with other objects that share the same symbols or refers to the same personification.

Moreover, the possible link between the tangible and intangible elements (object and rituals) on the base of their sign systems and the relations with a performative event, open up the possibility to describe a partial view of the habitus of production and use of the built and visual heritage.

\section{Limitations}

It is important to underline that these are preliminary results, and more work need to be done in relation of the interconnection between social communities and interpretative work, because even if at a descriptive level the interpretation is actor-based, in reality, the interpretation is social mediated, and would not make sense to distinguish between these two levels.

\section{References}

Baca, M., Harpring, P., Lanzi, E., McRae, L., \& White-side, A. (2006). Cataloging cultural objects. Chicago, IL: American Library Association. https:// doi.org/10.1016/

$$
\text { j.lcats.2007.07.011 }
$$

Bal, M., \& Bryson, N. (1991). Semiotics and art history. The Art Bulletin, 73(2), 174-208. https://doi.org/ 10.1080/00043079.1991.10786750

Bekiari, C., Doerr, M., Le Bœuf, P., \& Riva, P. (2015).

FRBR object-oriented definition and mapping from FRBRER, FRAD and FRSAD (2nd ed.). Retrieved from https://www.ifla.org/files/assets/cataloguing/frbr/ frbroo_v2.2.pdf

Bourdieu, P. (1977). Outline of a theory of practice. Cambridge, UK: Cambridge University Press.

Carboni, N., \& De Luca, L. (2016). Towards a conceptual foundation for documenting tangible and intangible elements of a cultural object. Digital Applications in Archaeology and Cultural Heritage, 3(4), 108-116.

Carr, A. W., \& Nicolaïdès, A. (2012). Asinou across time Washington, DC: Dumbarton Oaks Research Library and Collection.

CIDOC Conceptual Reference Model. (2015). CIDOC conceptual reference model (6th ed., pp. 1-201). Retrieved from http://www.cidoc-crm.org/sites/default/files/cidoc_ crm_version_5.0.4.pdf-

D’Andrea, A., \& Ferrandino, G. (2007, April). Shared iconographical representations with ontological models. Paper pre-sented at the 35th International Conference on Computer Applications and Quantitative Methods in Archaeology, Berlin, Germany.

Daquino, M., Mambelli, F., Peroni,

S., Tomasi, F., \& Vitali, F.

(2016). Enhancing semantic expressivity in the cultural heritage domain: Exposing the Zeri photo archive as linked open data. Retrieved from arXiv.org

Daquino, M., \& Tomasi, F. (2015). Historical context ontol-ogy (HiCO) - A conceptual model for describing context 
information of cultural heritage objects. In E. Garoufallou, R. J. Hartley, \& P. Gaitanou (Eds.), Metadata and Semantics Research. (Vol. 544, pp. 424-436). Berlin, Germany: Springer International Publishing.

De Luca, L., De Domenico, F., Lombardo, J., Stefani, C., Pierrot-Deseilligny, M., \& Wang, F. (2013). When script engravings reveal a semantic link between the conceptual and the spatial dimensions of a monument: The case of the tomb of Emperor Qianlong (Vol. 1, pp. 505-512). Paper presented at the 2013 Digital Heritage International Congress, Marseille, France: IEEE. https://doi.org/10.1109/DigitalHeritage.2013.6743790

Doerr, M. (2003). The CIDOC conceptual reference module: An ontological approach to semantic interoperability of metadata. AI Magazine, 24(3), 75-92. https://doi.org/10.1609/aimag.v24i3.1720

Doerr, M., \& Hiebel, G. (2013). CRMgeo: Linking the CIDOC CRM to GeoSPARQL through a spatiotemporal refinement. (No. ICS-FORTH/TR-435). ICS-FORTH. Retrieved from http://www.ics.forth.gr/isl/CRMext/CRMgeo/docs/TR435CRMgeo.pdf.

Duits, R. (2014). A new resource based on old principles: The Warburg Institute iconographic database. Visual Resources, 30(3), 263-275. https://doi.org/10.1080/ 01973762.2014 .936104

Eco, U. (1979). Lector in fabula: La cooperazione interpretativa nei testi narrativi. Milan, Italy: Bompiani.

https://doi.org/10.4159/harvard.9780674060876 Gangemi, A., \&

Mika, P. (2003). Understanding the semantic web through descriptions and situations. In R. Meersman, Z. Tari, \& D. C. Schmidt (Eds.), On the move to meaningful Internet systems: CoopIS, DOA, and ODBASE (pp. 689-706). Berlin, Germany: Springer. https:// doi.org/10.1007/978-3-540-39964-3_44

Garnier, F. 1.-2. A. D. T. (1984). Thesaurus iconographique. Paris: le Léopard d'or. Retrieved from

http://gallica.bnf.fr/ark:/12148/bpt6k33231071 Gombrich, E.

H. (1994). The image and the eye. London, UK: Phaidon Press.

Gonano, C. M., Tomasi, F., Mambelli, F., Vitali, F., \& Peroni, S. (2014, September). Zeri e LODE. Extracting the Zeri photo archive to linked open data-Formalizing the conceptual model (pp. 289-298). Paper presented at the IEEE/ACM Joint Conference on Digital Libraries, London, UK: IEEE. https://doi.org/10.1109/JCDL.2014.6970182

Guarino, N. (1998, June). Formal ontology in information systems. Presented at the Formal Ontology in Information Systems, Trento: Amsterdam; Washington, DC: IOS Press; Tokyo: Omsha.

Hoekstra, R. (2009). Ontology representation-Design patterns and ontologies that make sense. Amsterdam, The Netherlands: IOS Press.
Kettula, S., \& Hyvönen, E. (2012, September). Process-centric cataloguing of intangible cultural heritage. Paper presented at the CIDOC 2012, Helsinki, Norway.

Lemonnier, P. (2012). Mundane objects: Materiality and nonverbal communication (Vol. 10). Walnut Creek, CA: Left Coast Press

Lubas, R., Jackson, A., \& Schneider, I. (2013). The metadata manual. Oxford, UK: Chandos Publishing.

Mambelli, F. (2014). Una risorsa online per la storia dell'arte: Il database della Fondazione Federico Zeri. Quaderni DigiLab, 3(1), 113-125.

Panofsky, E. (1939). Studies in iconology. Humanistic themes in the art of the Renaissance. New York, NY: Harper \& Row.

Peroni, S., Shotton, D., \& Vitali, F. (2012, September). Scholarly publishing and linked data: Describing roles, statuses, temporal and contextual extents. Paper presented at the 8th International Conference on Semantic System, New York, NY, ACM Press. https://doi.org/10.1145/2362499.2362502

Peroni, S., \& Shotton, D. M. (2012). FaBiO and CiTOOntologies for describing bibliographic resources and citations. Journal of Web Semantics: Science, Services and Agents on the World Wide Web, 17, 33-43.

Polidoro, P. (2008). Che cos'è la semiotica visiva. Rome, Italy: Carocci editore.

Reist, I., Farneth, D., Stein, R. S., \& Weda, R. (2015, September). An introduction to PHAROS: Aggregating free access to 31 million digitized images and counting. Paper presented at the CIDOC. 2015, New Delhi, India. Retrieved from http:// network.icom.museum/fileadmin/user_upload/minisites/ cidoc/BoardMeetings/CIDOC_PHAROS_Farneth-SteinWeda_1.pdf.

Sowa, J. F. (2000). Knowledge representation. Pacific Grove, CA: Brooks/Cole.

Stylianou, A., \& Stylianou, J. A. (1985). The painted churches of Cyprus. London, UK: A. G. Levantis Foundation.

Tzouveli, P. K., Simou, N., Stamou, G. B., \& Kollias, S. D. (2009). Semantic classification of Byzantine icons. IEEE Intelligent Systems, 24(2), 35-43. http://doi.org/10.1109/MIS.2009.34

van de Waal, H. (1973). Iconclass. An iconographic classification system (L. D. Couprie, E. Tholen, \& G. Vellekoop, Eds.). Amsterdam, The Netherlands: North-Holland Publishing Company.

van Straten, R. (1986). Panofsky and ICONCLASS. Artibus Et Historiae, 7(13), 165. https://doi.org/10.2307/1483254

van Straten, R. (1994). An introduction to iconography. New York, NY: Taylor \& Francis.

Zúñiga, G. L. (2001, October). Ontology-Its transformation from philosophy to information systems. Paper presented at the International Conference on Formal Ontology in Information Systems, New York, NY: ACM Press. https://doi.org/10.1145/505168.505187 